\title{
Experimental storm surge forecasting in the Bay of Bengal
}

\author{
H. S. Mashriqui ${ }^{1}$, G. P. Kemp ${ }^{1}$, I. van Heerden ${ }^{1}$, J. Westerink ${ }^{2}$, \\ Y. S. Yang ${ }^{1} \&$ B. D. Ropers-Huilman ${ }^{3}$ \\ ${ }^{1}$ Hurricane Center, Louisiana State University, USA \\ ${ }^{2}$ University of Notre Dame, USA \\ ${ }^{3}$ Center for Computation \& Technology, Louisiana State University, USA
}

\begin{abstract}
The fully parallel Advanced Circulation (ADCIRC) model has been used experimentally since 2002 for storm operations support in the Gulf of Mexico. The modeling team at LSU has demonstrated a capability to provide multiple, near real-time forecast permutations that can improve preparedness and public safety response. Coastal areas of Bangladesh and India adjacent to the Bay of Bengal are vulnerable to storm surges during tropical cyclone passages that can cause more than 300,000 deaths per event (1970 Meghna Estuary super cyclone). Early, detailed and reliable predictions of storm effects on population centers, levees and evacuation routes are vital to saving lives. The LSU Hurricane Center will provide modeling support for the Bay of Bengal basin and expects to build partnerships with interested agencies. This will be the first modeling program capable of forecasting cyclone surge propagation for a 3 to 5 day period across the entire Bay of Bengal. The model domain includes the entire Bay of Bengal and part of the Northern Indian Ocean, the east coast of India, all of the coasts of Bangladesh, Sri Lanka and Myanmar (Burma), as well as the islands of Andaman and Nicobar. The finite element mesh includes more than 363399 elements and 186981 nodes, particularly along coastlines, in river channels and around islands.
\end{abstract}

Keywords: ADCIRC, Bay of Bengal, Storm Surge, GIS.

\section{Introduction}

The Bangladesh and East Indian coasts have been formed by distributaries of the Ganges and Brahmaputra Rivers that join in Bangladesh to form the Meghna. 
Deltaic lands built by the rivers are low-lying, averaging only 1 to $3 \mathrm{~m}$ above sea level, but are still home to millions. They are fronted by a wide and shallow continental shelf. Cyclones making landfall over shallow water can combine with the $2 \mathrm{~m}$ to $3 \mathrm{~m}$ astronomical tides to produce storm surges in excess of $7 \mathrm{~m}$ (Salek [1]). Embankments or levees built to protect people are overtopped or seriously damaged with every major storm and this leads to tragedy when thousands are trapped by rising waters. Louisiana, on the north-central coast of the Gulf of Mexico in the United States has a similar deltaic landscape and hurricane threat. There, numerical hurricane surge prediction models are beginning to be used to provide early warning to low-lying areas and guide evacuation and rescue operations (Winer and Naomi [2]).

ADCIRC is a parallel two-dimensional, depth-integrated, finite element hydrodynamic circulation model (Westerink et al [3]) that is forced by an atmospheric cyclone model (Cardone et al [4]) for simulations of circulation and cyclone surge propagation in coastal areas. ADCIRC is ideal for coasts with large inter-tidal zones or occasionally flooded areas because of attention given to the consequences of element wetting and drying (Winer and Naomi [2]). When provided with a relatively small number of storm and storm track attributes that are available from the U.S. Navy Joint Typhoon Warning Center (JTWC) in the Bay of Bengal, ADCIRC can produce surge forecasts extending days into the future in a matter of a few hours. Significant experience and insight was gained as to how to run the very large ADCIRC/Southern Louisiana model in forecast mode. Based on our experience it appears that the 1-day ramps used for the forcing functions worked quite well. It was noted that the tides needed to be spun up prior to the storm entering the Gulf, which requires about 20 days of simulation from a cold start. This year, for the first time, we will apply a version of the Advanced Circulation (ADCIRC) model that has been used to forecast storm surge for the East and Gulf coasts of the United States to the Bay of Bengal.

Here, we demonstrate the early warning potential of an ADCIRC model for the Bay of Bengal. The model domain introduced here includes the entire Bay of Bengal and part of the Northern Indian Ocean, the east coast of India, all of the coasts of Bangladesh, Sri Lanka and Myanmar (Burma), as well as the islands of Andaman and Nicobar (fig. 1). The unstructured finite element mesh includes more than 363399 elements and 186981 nodes, clustered along coastlines, in river channels and around islands (fig. 2). In benchmark tests using 64 computer processors, this model has run a 5-day forecast in less than 2 hour of cpu time.

The Bay of Bengal is an underserved area, in contrast to other cyclone prone parts of the world. United Nations agencies such as World Meteorological Organization (WMO) have yet to implement an advanced near real-time forecasting model in the Bay of Bengal. Here we describe two methods that were used to calibrate and validate the Bay of Bengal ADCIRC model. First, we reproduced tidal constituents across the domain, and, second, simulated the April 1991 cyclone that caused 138,000 fatalities in Bangladesh (Mashriqui et al [5]). Finally, we discuss a web-based procedure for integrating 3 to 5 day cyclone storm surge forecasting across the entire Bay of Bengal into a warning system. 


\section{Earlier models of the Bay of Bengal}

Numerical models have been used to hindcast cyclone storm surge for at least four decades, including efforts to simulate observations from the Bay of Bengal (see Murty et al [6] and Flather [7]). Murty et al [6] provides a review of earlier Bay of Bengal models that were used to hindcast past events, typically driven by idealized and symmetric cyclones of constant intensity moving along straightline tracks. The domains of earlier Bay of Bengal models were confined to the immediate vicinity of the coast (Flather [7], Salek [1]). Regional or local models such as these require ocean and land boundary conditions to be supplied either by in situ tide gauges or by reference to basin-scale or global models (Blain et al [8]). While informative, the hindcasting approach has limited utility for forecasting when the track and storm intensities are changing over time, and boundary conditions are not immediately available.

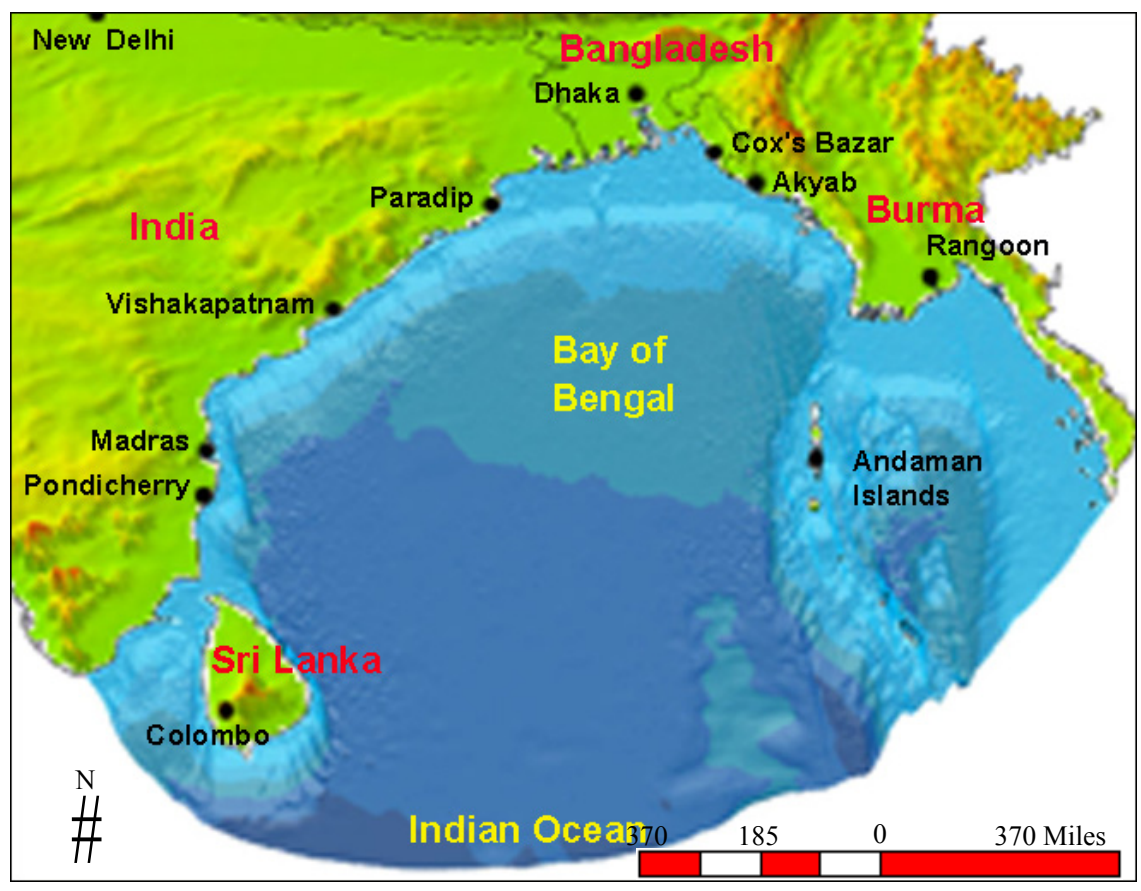

Figure 1: Study area location in the Bay of Bengal basin (Mashriqui et al [5]).

As shown by Blain et al [8], a truly predictive capability for elevation and flow in coastal regions requires that all important scales of motion be sufficiently resolved in the numerically discrete form of the governing equations. Blain et al [8] clearly showed that storm surge model domains on the continental shelf must be large relative to the size of the storm to avoid significantly underestimating the primary storm surge response. On the other end of the spatial scale, Blain et al [8] showed in a grid convergence study that near-coastal resolution is the most 
critical factor for accuracy of storm surge computations. Typically, a higher degree of grid refinement is required as the landward boundary is approached. Earlier ADCIRC model developed by Mashriqui et al [5] extended the model domain to the Northern Indian Ocean. Research reported in this paper is a continuation of that earlier work. Current model domain has been extended to include part of the island of Sumatra to avoid complex boundary tide when it propagates from the Indian Ocean to the Bay of Bengal. Wetting and drying capabilities were also added to the current model domain.

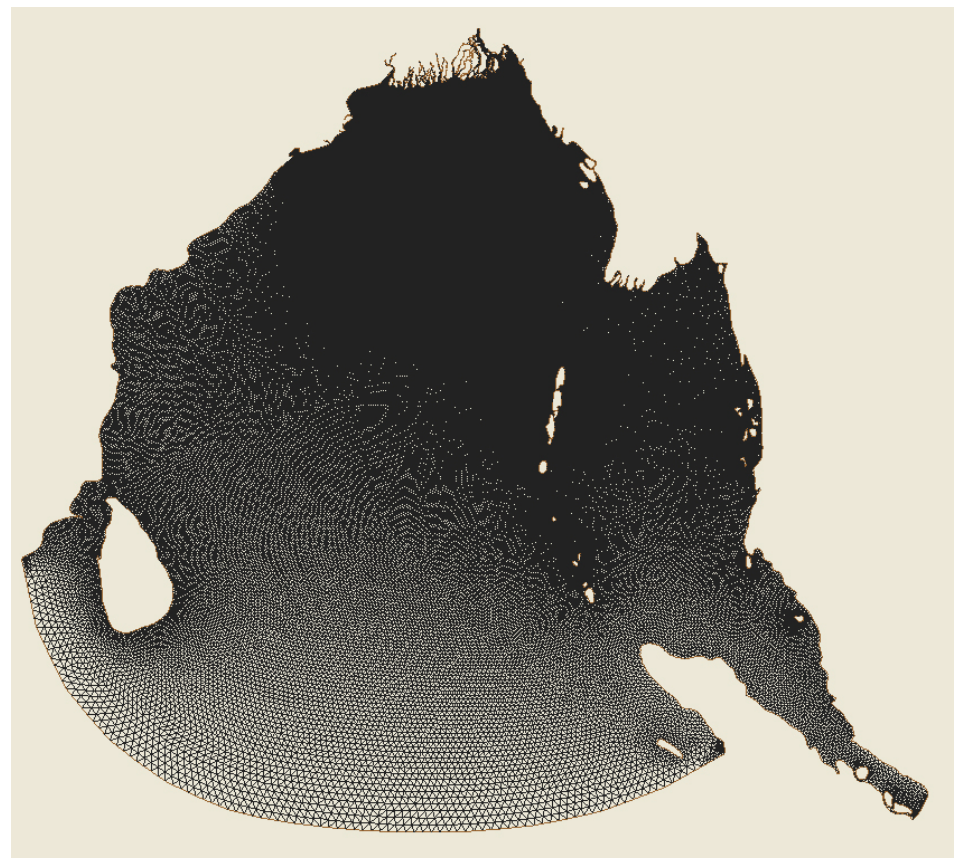

Figure 2: The extended ADCIRC finite elements grid of the model domain.

\section{Methods}

The model used by Mashriqui et al [5] has a wide, deep open ocean boundary along the south boundary. Depth in the Bay of Bengal decreases south to north, from a maximum of 4,000 $\mathrm{m}$ (fig. 1). The Andaman and Nicobar Islands form a discontinuous barrier extending south of Myanmar, that separates a shallow eastern portion from the rest of the Bay. The Meghna River enters the model domain from the north at a discharge boundary. We developed the geometry of the model domain from the digital world map (ESRI ArcView sample data). Bathymetry was obtained from the ETOPO2 database from the National Center for Atmospheric Research (NGDC [9]). Near-shore and coastline bathymetry were obtained from the DMA and British admiralty charts that were hand- 
digitized and edited. The finite element grid used by Mashriqui et al [5] contains 63,407 nodes and 122,822 finite elements. The level of grid refinement is based on grid convergence studies as well as on the response functions obtained from previous computations (Blain et al $[8,10]$ ). In general, the deepest waters in the Bay of Bengal are relatively coarsely discretized, while the continental shelf waters and regions of detailed interest, in this case Ganges delta and vicinity, are very finely resolved. The largest finite elements in this grid have a size of (40) $\mathrm{km}$ while the finest elements are sized $150 \mathrm{~m}$. Water level along the open boundary is obtained from global tidal information and is represented by the five major constituents (M2, S2, N2, O1 and K1) from Le Provost et al [11] FES95.2 database. This database was developed using a global tidal model and has been found to perform very well in deep ocean waters.

For our tidal calibration, we sought to reproduce amplitude and phase of each tidal constituent predicted by the Colorado University and University of Texas global models (http:/www.ssc.erc.msstate.edu/Tides2D). To do this, the model was spun up from homogeneous initial conditions using a 20-day time ramp (Westerink and Luettich [12]). The very smooth hyperbolic tangent time ramp function was applied both to the boundary conditions and direct forcing functions. A 20-day spin up is more than adequate for all constituents of interest (Westerink and Luettich [12]). Simulations with $5 \mathrm{~s}$ time-steps were run for 90 days but only the last 60 days were used.

\section{Cyclone hindcasting}

The U.S. Navy Joint Typhoon Warning Center (JTWC) provided an excellent dataset describing the April 1991 cyclone that struck the coast of Bangladesh causing thousands of fatalities (JTWC annual report, 1991). This track and central pressure time-series was input into ADCIRC's PBL wind model. The ADCIRC model that had been parameterized against the tidal constituents, as described above, was not changed for the cyclone hindcast. Flather [7] provides summaries of field observations of the resulting storm surge. Flather's [7] distribution and that predicted by ADCIRC both show that maximum elevation was reached in the strait between Kutubdia Island and the Bangladesh mainland south of Chittagong (fig. 3). ADCIRC predicted the highest surge to be $4.23 \mathrm{~m}$ above mean sea level (MSL). Flather [7] gives a $4 \mathrm{~m}$ contour for storm surge residual elevation that includes all of Kutubdia Island, suggesting very reasonable agreement with ADCIRC. Again, the April 1991 cyclone was simulated using the new extended model domain with wetting and drying capabilities. Patterns and sequences of flooding of the east coast of Bangladesh near Chittagong were shown in fig. 4.

\section{Forecasting of future cyclones}

The fully parallel ADvanced CIRCulation (ADCIRC) model has been used experimentally since 2002 for storm operation support in the Gulf of Mexico. 
The ADCIRC model was calibrated using two different hurricanes that made landfall in Louisiana, Hurricanes Betsy (1965) and Andrew (1992). The ADCIRC model showed a very good correlation with the actual storm surges measured during these storms. The ADCIRC Southern Louisiana storm surge flood model is the most sophisticated, detailed and accurate model of coastal flooding in the world.
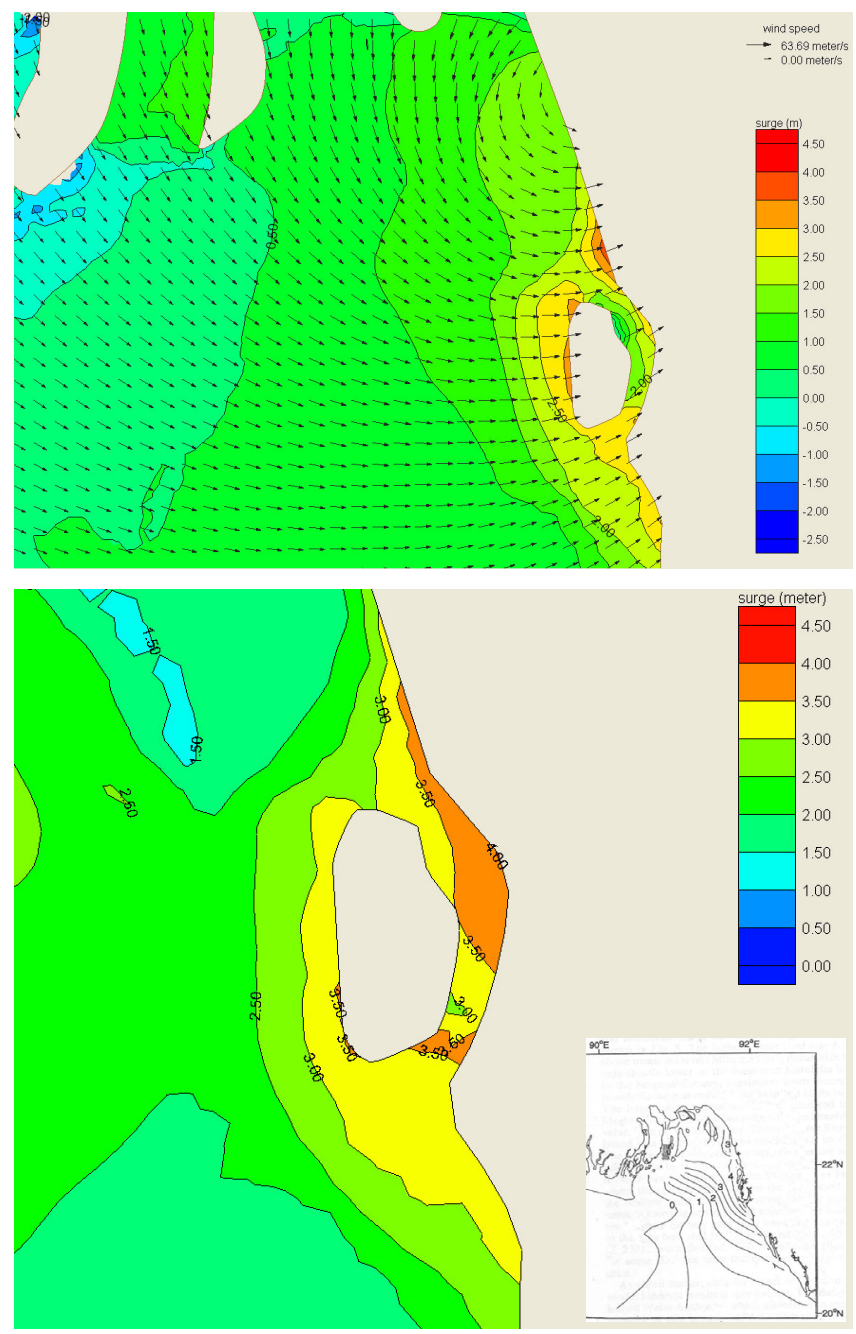

Figure 3: ADCIRC simulated storm surge before landfall. The arrows indicate wind vectors; the colors indicate water levels (top). ADCIRC maximum surge height near Kutubdia Island compared to Flather [7] (bottom, inset). 


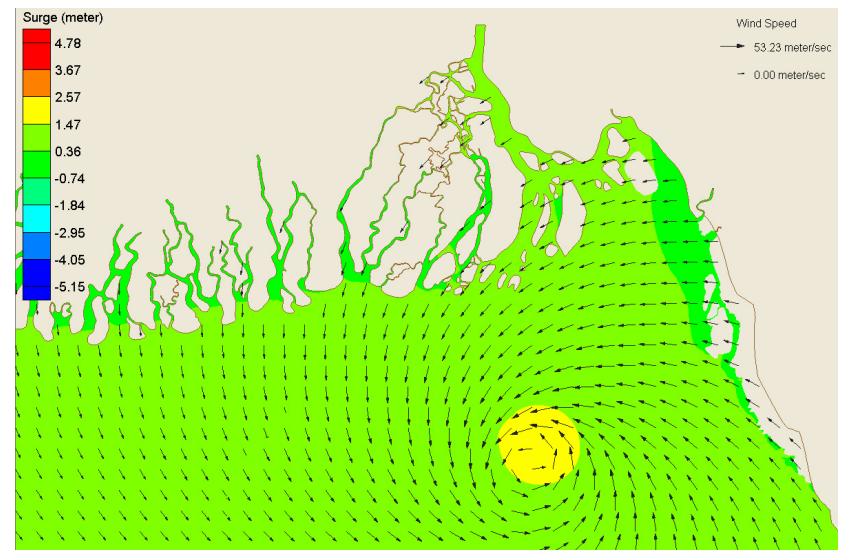

(a) long before the landfall

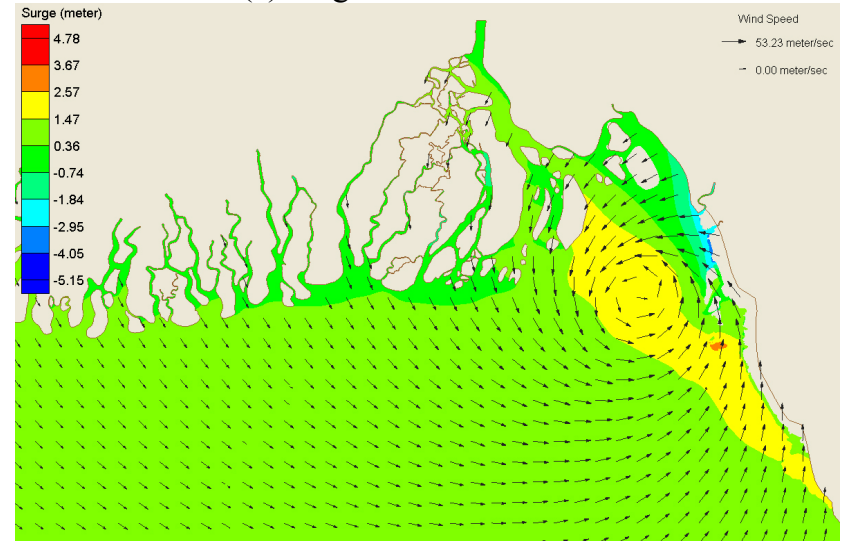

(b) before landfall, surge is inundating islands from the south



(c) during landfall, surge is inundating islands from the south and the west

Figure 4: ADCIRC simulated storm surge before and during landfall. The arrows indicate wind vectors; the colors indicate water levels (top). 


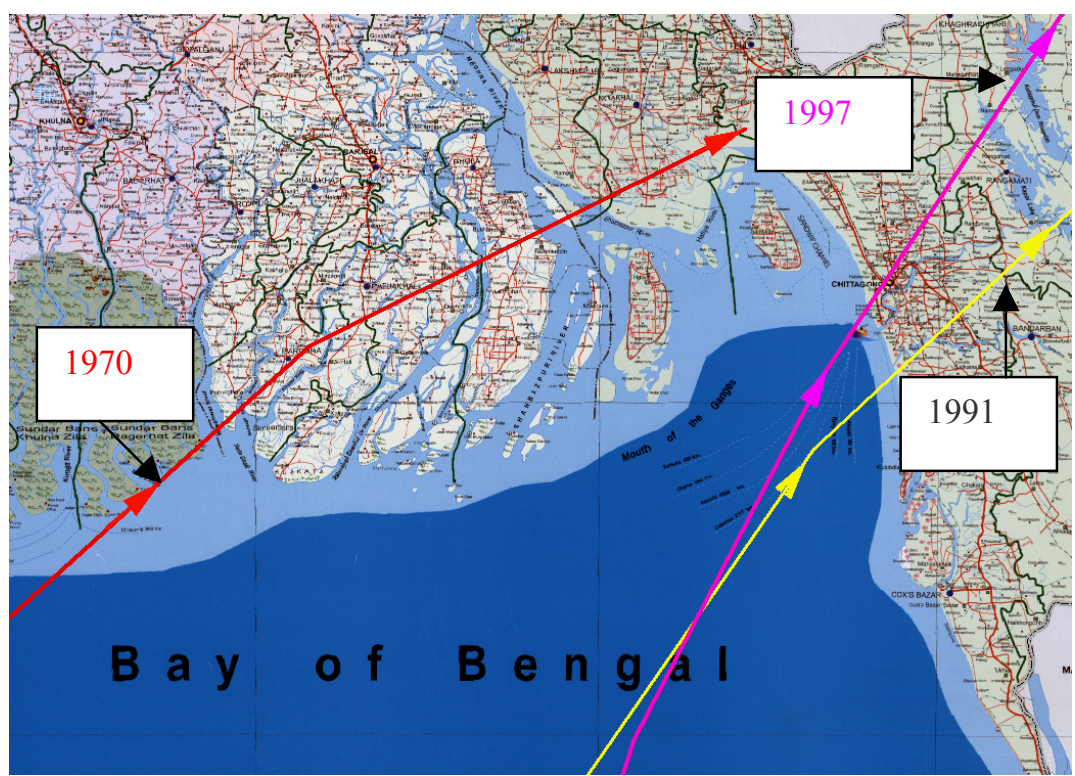

Figure 5: November 1970, April 1991 and 1997 cyclone landfall location from the best track data of JTWC super imposed on a local highresolution map. Note the path of the eye over local cites.

The modeling team at LSU has demonstrated a capability to provide multiple, near real-time forecast permutations that can meet decision-makers' needs to improve preparedness and public safety response. The LSU Hurricane Center will process JWTC forecast data and provide similar experimental modeling support for the Bay of Bengal basin beginning with the 2005 cyclone season to improve and demonstrate model capabilities. The objectives of this modeling program are to provide 3-to-5-day forecasts of storm surge height and propagation and to illustrate them on a web-accessible (www.stormsurg.lsu.edu), very high-resolution coastal map of the Bay of Bengal (fig. 5). Storm surge computations will be made on a new LSU CCT supercomputer ("SuperMike") that is among the fastest academic clusters in the world, a Beowulf-class supercomputer with 1,024 processors. Use of the supercomputer technology and GIS in this program makes this modeling program unique and the first model ever to simulate storm surge in the Bay of Bengal in a forecast mode.

\section{Conclusions and recommendations}

Improved forecasts of storm surge coupled to more timely and accurate warnings are important prerequisites for saving lives in the heavily populated coastal regions surrounding the Bay of Bengal. Based on the preliminary results presented here, ADCIRC appears to offer great promise if forecast results can be disseminated quickly enough as a storm approaches landfall. More detailed 
information on bathymetry and land elevations in the vulnerable areas would allow the simulation of inundation to be improved. The Bay of Bengal is an underserved area, in contrast to other cyclone prone parts of the world. We strongly recommend that United Nations agencies such as World Meteorological Organization (WMO) implement an advanced near real-time forecasting model in the Bay of Bengal. Murty and Henry [13] recommended 20 years ago that an international effort be organized for the purpose of collecting and publishing complete dossiers of relevant data on major surges in the Bay of Bengal. About 4 large surges occur each year within the Bay of Bengal ADCIRC domain, but since each affects only a small portion of coastline, Murty and Henry [13] concluded that this data-gathering scheme would have to be pursued for up to 2 decades to accumulate an adequate body of verification data. We believe that a tool like ADCIRC could greatly reduce the time necessary, as it would be possible to generalize more efficiently from fewer storm dossiers.

\section{References}

[1] Salek, J. A., Coastal trapping and funneling effect on storm surges in the Meghna estuary in relation with the cyclones hitting Noakhali-Cox's Bazar coast of Bangladesh. J. Phys. Oceanogr., 28, pp. 227-249, 1998.

[2] Winer, H. \& Naomi, A., Advanced Circulation Model - A Hurricane Protection Design Tool. Solutions to Coastal Disasters 2005, ASCE.

[3] Westerink, J.J., Luettich, R.A. \& Scheffner, N.W., ADCIRC: an advanced three-dimensional circulation model for shelves coasts and estuaries, report 3: development of a tidal constituent data base for the Western North Atlantic and Gulf of Mexico, Dredging Research Program Technical Report DRP-92-6, U.S. Army Engineers Waterways Experiment Station, Vicksburg, MS, 154p. 1993.

[4] Cardone, VJ., Greenwood, C.V. \& Greenwood, J.A., Unified program for the specification of hurricane boundary layer winds over surfaces of specified roughness, Report CR.CERC-92-1, Coastal Eng. Res. Cent., U.S. Army Eng., Vicksburg, Miss., Sept., 1992.

[5] Mashriqui, H.S., Kemp, G.P., van Heerden, I, Westerink, J, RopersHuilman, B, Streva, K., Binselam, A , \& Seok, Y.S., Bay of Bengal Cyclone Surge Modeling Program: Use of Super Computer Technology and GIS for Early Warning. 13th International Conference on Geoinformatics, August 17-19, 2005, Toronto, Canada.

[6] Murty, T S., Flather, R.A. \& Henry, R.E., The storm surge problem in the Bay of Bengal. Progress in Oceanography, 16, pp. 195-233, 1986.

[7] Flather, R. A., A storm surge prediction model for the northern Bay of Bengal with application to the cyclone disaster in April 1991. Journal of Physical Oceanography 24, 172-190, 1994.

[8] Blain, C.A., Westerink, J.J. \& Luettich, R.A. , Domain and grid sensitivity studies for hurricane storm surge predictions, Computational Methods in Water Resources X, eds. A. Peters et al., Heidelberg, July, 1994. 
[9] National Geographic Data Center (NGDC), ETOP02: Bathymetry/ Topography Data, U.S. Dep. of Com., Washington, D.C., 2004.

[10] Blain, C.A., Westerink, J.J. \& Luettich, R.A., Application of a domain size and gridding strategy in the prediction of hurricane storm surge, Computer Modeling of Seas and Coastal Regions II, eds. C.A. Brebbia et al., Computational Mechanics Publications, Southampton, pp. 301-308, 1995.

[11] Le Provost, C., Bennett, A.F. \& Cartwright, D.E., Ocean tides for and from TOPEX/Poseidon, Science, 267, 639-642, 1995.

[12] Westerink, J.J. \& Luettich, R.A., Tide and storm surge predictions in the Gulf of Mexico using model ADCIRC-2D, Report to the US Army Engineer Waterways Experiment Station, July, 1991.

[13] Murty, T. S. \& Henry, R. F., Recommendations for improving storm surge prediction in the Bay of Bengal area. Report to WMO-ESCAP Panel on Tropical Cyclones. 11 pp, 1983. 